\title{
Identification of two genetic groups in Bacteroides fragilis by multilocus enzyme electrophoresis: distribution of antibiotic resistance (cfiA, cepA) and enterotoxin (bft) encoding genes
}

\author{
Michaela Gutacker, Claudio Valsangiacomo and Jean-Claude Piffaretti
} Author for correspondence: Jean-Claude Piffaretti. Tel: +4191923 25 22. Fax: +41919220993.
e-mail: Jean-Claude.Piffaretti@ti.ch

Istituto Cantonale Batteriosierologico, Via Ospedale 6, 6904 Lugano, Switzerland

\begin{abstract}
Ninety-three Bacteroides fragilis strains of different origin were analysed by multilocus enzyme electrophoresis (MLEE). Fourteen of the 15 genetic loci analysed were polymorphic, whilst nucleoside phosphorylase was monomorphic. There was a mean of six alleles per locus and a mean genetic diversity of 0.393 . Cluster analysis identified 90 electrophoretic types (ETs) separated into two major phylogenetic divisions at a genetic distance of 0.70 . Division I consisted of 81 ETs carrying the endogenous class A $\beta$-lactamase gene cepA, whereas division II comprised 9 ETs carrying the class B $\beta$-lactamase gene cfiA, but not cepA. The presence of these two genes was assessed by PCR and the expression of the cfiA gene was investigated by determining the level of resistance to the antibiotic imipenem. MLEE showed a smaller genetic distance among the genotypes of the imipenem-resistant than among the imipenem-susceptible strains. No other particular cluster was observed. The enterotoxin gene (bft) was detected by PCR: DNA sequencing of the products obtained showed that the different bft alleles (bft-1, bft-2 and bft-3) were scattered randomly troughout the phylogenetic tree. No association between distinct clones and clinical manifestations (sepsis, abscesses, diarrhoea), geographical origin or host origin (human or animal) could be found.
\end{abstract}

Keywords: Bacteroides fragilis, multilocus enzyme electrophoresis, cepA, $c f A$, enterotoxin

\section{INTRODUCTION}

Species of the genus Bacteroides are found in the normal human and animal gastrointestinal flora. Occasionally, these Gram-negative, anaerobic bacilli can cause human invasive infections, predominantly bacteraemia, or intra-abdominal and wound infections after surgery of the gastrointestinal or urogenital tract. These microorganisms carry genes encoding products involved in pathogenicity, such as enzymes synthesizing a capsular polysaccharide which inhibits phagocytosis and induces abscess formation (Tzianabos et al., 1994), fimbriae and

Abbreviations: $\mathrm{ET}$, electrophoretic type; $\mathrm{ETBF}$, enterotoxin-producing Bacteroides fragilis; MLEE, multilocus enzyme electrophoresis (abbreviations for the enzymes studied by MLEE are defined in Methods).

The GenBank accession numbers for the sequences determined in this work are AF197508-AF197534. pili promoting adherence to epithelial cells and mucus, neuraminidase, and an enterotoxin (Akimoto et al., 1994; Brook \& Mihal, 1991; Brook et al., 1992; Duimstra et al., 1991; Kleivdal \& Hofstad, 1995; Moncrief et al., 1995; Myers et al., 1989; Russo et al., 1990; Sack et al., 1992; Smith \& Callihan, 1992).

Previous studies have suggested a role of enterotoxinproducing Bacteroides fragilis (ETBF) in diarrhoeal disease of children (Sack et al., 1994; San Joaquin et al., 1995). However, the high proportion of healthy carriers (Pantosti et al., 1994, 1997a) and the frequent association of ETBF with bacteraemia (Kato et al., 1996), and thus not exclusively with diarrhoeal disease, make it difficult to define the enteric pathogenic importance of this micro-organism. Franco et al. (1997) and Chung et al. (1999) have shown that the metalloprotease enterotoxin encoded by the bft gene alters the morphology of intestinal epithelial cells and may thus contribute to the 
virulence of B. fragilis (Franco et al., 1997). Recent studies have shown the existence of more than one allele of the $b f t$ gene $[b f t-1, b f t-2$ (Franco et al., 1997), bft-3 (Kato et al., 2000) and bft-Korea (Chung et al., 1999)], and the localization of this gene on the fragilysin pathogenicity islet. However, although ScottoD'Abusco et al. (1998) suggested a higher association of $b f t-2$ with diarrhoea in children, little has been done to investigate a preferential correlation between one specific $b f t$ allele and a clinical manifestation.

DNA-DNA hybridization experiments have shown two DNA-homology groups of B. fragilis (I and II), with about $80 \%$ of strains isolated in clinical studies assigned to homology group I (Johnson, 1978). Similarly, two genotypically distinct $B$. fragilis groups have been identified on the basis of ribotyping, restriction fragment length polymorphism (RFLP), PCR-generated fingerprinting, insertion sequence (IS) content and 16S rRNA sequence alignments (Moraes et al., 1999; Kleivdal \& Hofstad, 1995; Podglajen et al., 1995; Ruimy et al., 1996; Smith \& Callihan, 1992). One group was characterized by the presence of the cfiA gene (encoding a metallo- $\beta$-lactamase of Ambler's class B) and the absence of the cepA gene (encoding a $\beta$-lactamase of Ambler's class A). Three specific insertion sequence elements, IS1186, IS942 and IS4351, providing the promoter region for the cfiA gene, were shown to be confined to this group (Podglajen et al., 1995). The second group was characterized by the absence of the cfiA gene and of the associated insertion sequences, the frequent presence of the cepA gene, and a higher genetic heterogeneity (Podglajen et al., 1995; Ruimy et al., 1996). By including strains obtained from Johnson (1978) in their 16S rRNA sequence comparison, Ruimy et al. (1996) showed that the two groups described above could be related to the DNA homology groups II and I, respectively. Despite these findings, there is as yet no information dealing with the genetic relationship between invasive and noninvasive strains, human and animal strains and strains of different geographical origin.

Multilocus enzyme electrophoresis (MLEE) estimates the overall genetic relatedness among strains by indicating allele variation in a random sample of chromosomally encoded metabolic housekeeping enzymes (Selander et al., 1986). This technique has already been extensively used in our laboratory for the study of other bacterial species (Aeschbacher \& Piffaretti, 1989; Balmelli \& Piffaretti, 1996; Boerlin et al., 1992, 1991; Boerlin \& Piffaretti, 1995; Piffaretti et al., 1989).

In the present study, we used MLEE to analyse the genetic diversity and the population structure of $B$. fragilis. This may be relevant to identify genotypes, clones or cryptic genospecies nonrandomly associated with clinical manifestations, antibiotic resistance, enterotoxin production or geographical origin.

\section{METHODS}

Bacterial strains. Ninety-three Bacteroides fragilis strains, one Bacteroides ovatus, one Bacteroides uniformis, three
Bacteroides vulgatus and one Porphyromonas gingivalis, originating from different countries, were investigated (Table 1). This collection included human invasive isolates from our region (the Southern part of Switzerland) and strains isolated from patients' stools, invasive and noninvasive strains from different geographical regions (Switzerland, France, Norway, the United States and Japan), strains producing enterotoxin, invasive isolates from animals, and one reference strain of $B$. fragilis. Strains were routinely identified by the presence of catalase activity and by API 20A (BioMérieux). In isolates showing a genetic distance higher than 0.60 by MLEE, the identification was further confirmed by $16 \mathrm{~S}$ rRNA sequencing.

Culture conditions and specimen storage. Strains were grown on Columbia blood agar plates enriched with vitamin $K_{1}$. Cultures were incubated for $36 \mathrm{~h}$ at $37^{\circ} \mathrm{C}$ in an anaerobic chamber (Scholzen) containing an atmosphere of $5 \% \mathrm{CO}_{2}$, $10 \% \mathrm{H}_{2}, 85 \% \mathrm{~N}_{2}$. Bacteria harvested from one plate were suspended in skim milk (Difco) and stored. One loopful was suspended in $200 \mu \mathrm{l}$ water for DNA extraction. For MLEE, bacteria from two plates were harvested into $1.5 \mathrm{ml}$ phosphate-buffered saline $(\mathrm{NaCl} 137 \mathrm{mM}, \mathrm{KCl} 2.6 \mathrm{mM}$, $\mathrm{Na}_{2} \mathrm{HPO}_{4} 4.3 \mathrm{mM}, \mathrm{KH}_{2} \mathrm{PO}_{4} 1.8 \mathrm{mM}$ ), pH 7.2 (PBS). All suspensions were stored at $-80{ }^{\circ} \mathrm{C}$.

Antibiotic susceptibility testing. Minimal inhibitory concentrations (MICs) of imipenem were determined on Brucella agar plates supplemented with $5 \%$ blood, using the E-test (AB Biodisk) according to the manufacturer's instructions. Strains for which the MIC was $>16 \mu \mathrm{g} \mathrm{ml}^{-1}$ were considered resistant to imipenem (Nagy et al., 1995).

Enzyme extraction. This was performed according to Loos et al. (1993) with slight modifications. Briefly, the B. fragilis suspensions in PBS were thawed and kept on ice during all manipulations to preserve the enzyme activity. The cells were lysed for $15 \mathrm{~min}$ in $50 \mathrm{mM} \mathrm{n}$-octyl $\beta$-D-glucopyranoside (Sigma) with constant stirring. The suspensions were then sonicated twice for $15 \mathrm{~s}$ (small tip setting $6.5 \%$ duty cycle, sonifier model MSE; N. Ziwy \& Cie) for complete cell disruption and to decrease viscosity. Finally, the lysates were centrifuged at $20000 \mathrm{~g}$ at $4{ }^{\circ} \mathrm{C}$ for $20 \mathrm{~min}$ and the supernatants were stored in $200 \mu \mathrm{l}$ aliquots at $-80^{\circ} \mathrm{C}$.

Enzyme electrophoresis. Bacterial lysates were thawed and subjected to gel electrophoresis under nondenaturing conditions in $10 \%$ starch gels (Connaught Laboratories, Fisher Scientific) as described by Selander et al. (1986) and Boerlin \& Piffaretti (1995). Out of 27 different enzymes tested with different electrophoretic buffers, 15 could be reliably used for MLEE of B. fragilis: nucleoside phosphorylase (NSP), phosphoglucose isomerase (PGI), guanosine deaminase (GDA), glutamate dehydrogenase, NAD-dependent (GD1), glucose-6-phosphate dehydrogenase (G6P), malate dehydrogenase (MDH), hexokinase (HEX), phosphoglucomutase (PGM), alanine-phenylalanine peptidase (AF), phenylalanine -proline peptidase (FP), with buffer system F (Tris/maleate, $\mathrm{pH}$ 8.2) described by Selander (1986); catalase (CAT), with

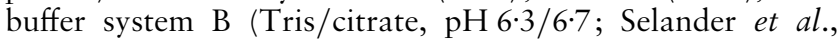
1986); indophenol oxidase (IPO), with buffer system C (borate, $\mathrm{pH} 8 \cdot 2 /$ Tris/citrate, $\mathrm{pH} 8 \cdot 7$; Selander et al., 1986); and esterase (EST), $\alpha$-galactosidase ( $\alpha \mathrm{GAL}), \alpha$-glucosidase ( $\alpha$ GLUS), with buffer system A (Tris/citrate, $\mathrm{pH} 8$; Selander et al., 1986). Enzyme staining was performed according to Selander et al. (1986). Specific staining procedures for $\alpha \mathrm{GAL}$, $\alpha$ GLUS and CAT were performed using the method of Harris \& Hopkinson (1976).

Another 12 enzymes were tested but not retained because of a lack of activity or uninterpretable results. 
Table 1. B. fragilis strains

\begin{tabular}{|c|c|c|c|c|c|c|}
\hline Isolate & ET & Biological origin & Geographical origin & $\begin{array}{c}\text { Genotypic } \\
\text { characterization }\end{array}$ & $\begin{array}{c}\text { MIC of } \\
\text { imipenem } \\
\left(\mu \mathrm{gl}^{-1}\right)\end{array}$ & Source* \\
\hline \multicolumn{7}{|l|}{ Division I } \\
\hline 3 & 1 & Ulcer & Switzerland, Ticino & cepA, bft-1 & $0 \cdot 064$ & IBS \\
\hline V15 2735 & 2 & Blood & Switzerland, Zürich & cepA & $0 \cdot 047$ & R. Zbinden \\
\hline D3251 & 3 & Blood, cat & Switzerland, Bern & cepA & $0 \cdot 094$ & J. Nicolet \\
\hline D1851 & 4 & Abdominal liquid, cat & Switzerland, Bern & cepA & $0 \cdot 047$ & J. Nicolet \\
\hline GAI20273 & 5 & Blood & Japan, Gifu & cepA & $0 \cdot 047$ & N. Kato \\
\hline F59D & 6 & Stool from patient 59 & Switzerland, Ticino & серA & $0 \cdot 19$ & IBS \\
\hline GAI97331 & 7 & Stool & Japan, Gifu & cepA & $0 \cdot 047$ & N. Kato \\
\hline 129 & 8 & Decubitus & Switzerland, Ticino & cepA & $0 \cdot 023$ & IBS \\
\hline 25458 & 9 & Blood & Norway, Bergen & cepA & $0 \cdot 047$ & T. Hofstad \\
\hline 47 & 10 & Appendicitis with abscess & Switzerland, Ticino & cepA & $0 \cdot 047$ & IBS \\
\hline AIP638 ${ }^{b}$ & 11 & Unknown & France, Paris & cepA & $0 \cdot 032$ & $\begin{array}{l}\text { Podglajen et al. } \\
\text { (1995) }\end{array}$ \\
\hline F120D & 12 & Stool from patient 120 & Switzerland, Ticino & cepA & $0 \cdot 064$ & IBS \\
\hline GAI97330 & 13 & Stool & Japan, Gifu & серA & $0 \cdot 25$ & N. Kato \\
\hline 70 & 14 & Intestinal fistula & Switzerland, Ticino & cep $A, b f t-1$ & $0 \cdot 047$ & IBS \\
\hline GAI20239 & 15 & Pus & Japan, Gifu & серA & $0 \cdot 19$ & N. Kato \\
\hline $1253-92$ & 16 & Stool, from healthy volunteer & Norway, Bergen & cep $A, b f t-2$ & $0 \cdot 064$ & T. Hofstad \\
\hline 1332 & 17 & Sigmoid pelvic abscess & France, Paris & серA & $0 \cdot 094$ & M. Sebald \\
\hline 31959 & 18 & Blood & Norway, Bergen & серA & $0 \cdot 047$ & T. Hofstad \\
\hline 30285 & 19 & Blood & Norway, Bergen & cepA & $0 \cdot 125$ & T. Hofstad \\
\hline VO5 6252 & 20 & Fistula abscess rectum & Switzerland, Zürich & cepA & $0 \cdot 047$ & R. Zbinden \\
\hline F70B & 21 & Stool from patient 70 & Switzerland, Ticino & cepA, bft-1 & $0 \cdot 064$ & IBS \\
\hline VO5 1019 & 22 & Syringe abscess, pus & Switzerland, Zürich & серA & $0 \cdot 125$ & R. Zbinden \\
\hline BLU 1696 & 23 & Blood & Switzerland, Zürich & cepA & $0 \cdot 19$ & R. Zbinden \\
\hline F126A & 24 & Stool from patient 126 & Switzerland, Ticino & cepA & $0 \cdot 75$ & IBS \\
\hline F126C & 25 & Stool from patient 126 & Switzerland, Ticino & cepA & 0.75 & IBS \\
\hline F126E & 25 & Stool from patient 126 & Switzerland, Ticino & серA & $0 \cdot 75$ & IBS \\
\hline 126 & 26 & Femur wound abscess & Switzerland, Ticino & серA & $0 \cdot 094$ & IBS \\
\hline GAI20246 & 27 & Blood & Japan, Gifu & $c e p A, b f t-1$ & $0 \cdot 125$ & N. Kato \\
\hline 118 & 28 & Wound abscess after appendectomy & Switzerland, Ticino & cepA & $0 \cdot 064$ & IBS \\
\hline F118A & 29 & Stool from patient 118 & Switzerland, Ticino & cepA & 0.094 & IBS \\
\hline L186 & 30 & Peritoneal liquid & Switzerland, Lausanne & серA & $0 \cdot 047$ & J. Bille \\
\hline 1320 & 31 & Blood & France, Paris & серA & $0 \cdot 064$ & M. Sebald \\
\hline 134 & 32 & Unknown & Switzerland, Ticino & cepA, bft-1 & $0 \cdot 75$ & IBS \\
\hline 1475 & 32 & Blood & France, Paris & cepA, bft-2 & $0 \cdot 094$ & M. Sebald \\
\hline 680 & 33 & Digestive tract & France, Paris & cep $A, b f t-2$ & $0 \cdot 38$ & M. Sebald \\
\hline GAI20261 & 34 & Ascites & Japan, Gifu & cepA, bft-1 & $0 \cdot 25$ & N. Kato \\
\hline 685 & 35 & Caecum abscess & France, Paris & cepA, bft-1 & $0 \cdot 25$ & M. Sebald \\
\hline 136 & 36 & Coproculture, Crohn's disease & France, Paris & cep $A, b f t-2$ & $0 \cdot 064$ & M. Sebald \\
\hline GAI97077 & 37 & Stool & Japan, Gifu & cepA, bft-1 & $0 \cdot 064$ & N. Kato \\
\hline L185 & 38 & Blood & Switzerland, Lausanne & серA & $0 \cdot 25$ & J. Bille \\
\hline GAI20241 & 39 & Periproptic abscess & Japan, Gifu & cepA & $0 \cdot 064$ & N. Kato \\
\hline D2383 & 40 & $\begin{array}{l}\text { Secretion from stomach puncture, } \\
\text { cat }\end{array}$ & Switzerland, Bern & cepA & $0 \cdot 064$ & J. Nicolet \\
\hline 1286 & 41 & Blood & France, Paris & серA & $0 \cdot 094$ & M. Sebald \\
\hline GAI 20240 & 42 & Pus & Japan, Gifu & $c e p A, b f t-3 \dagger$ & $0 \cdot 064$ & N. Kato \\
\hline 656 & 43 & Coproculture, digestive lymphoma & France, Paris & $c e p A, b f t-1$ & $0 \cdot 064$ & M. Sebald \\
\hline 646 & 44 & Digestive tract & France, Paris & cepA, bft-1 & $0 \cdot 25$ & M. Sebald \\
\hline L362 & 45 & Blood & Switzerland, Lausanne & cepA & $0 \cdot 125$ & J. Bille \\
\hline
\end{tabular}


Table 1 (cont.)

\begin{tabular}{|c|c|c|c|c|c|c|}
\hline Isolate & ET & Biological origin & Geographical origin & $\begin{array}{c}\text { Genotypic } \\
\text { characterization }\end{array}$ & $\begin{array}{l}\text { MIC of } \\
\text { imipenem } \\
\left(\mu \mathrm{g} \mathrm{ml}^{-1}\right)\end{array}$ & Source* \\
\hline 925 & 46 & Mesenteric ganglion & France, Paris & $c e p A, b f t-1$ & $0 \cdot 094$ & M. Sebald \\
\hline $5 \cdot 28$ & 47 & Unknown & Switzerland, Ticino & cepA & $0 \cdot 064$ & IBS \\
\hline V15 2715 & 48 & Wound after appendectomy & Switzerland, Zürich & серA & $0 \cdot 064$ & R. Zbinden \\
\hline F95A & 49 & Stool & Switzerland, Ticino & cepA & $0 \cdot 064$ & IBS \\
\hline VO8 12993 & 50 & Blood & Switzerland, Zürich & cepA & $0 \cdot 047$ & R. Zbinden \\
\hline 80 & 51 & $\begin{array}{l}\text { Swab of infected haematoma with } \\
\text { cutaneous fistula (deep wound, } \\
\text { pus) }\end{array}$ & Switzerland, Ticino & $\operatorname{cep} A$ & $0 \cdot 064$ & IBS \\
\hline 1402 & 52 & Blood & France, Paris & cepA & $0 \cdot 094$ & M. Sebald \\
\hline D2187 & 53 & Anal abscess, cat & Switzerland, Bern & cepA & $0 \cdot 064$ & J. Nicolet \\
\hline V12 6453 & 54 & Abdomen & Switzerland, Zürich & cepA & $0 \cdot 047$ & R. Zbinden \\
\hline 93 & 55 & Blood, patient 80 & Switzerland, Ticino & серA & $0 \cdot 047$ & IBS \\
\hline 1301 & 56 & Bone infection & France, Paris & cepA & $0 \cdot 38$ & M. Sebald \\
\hline 1511 & 57 & Vagina & France, Paris & $c e p A, b f t-1$ & $0 \cdot 094$ & M. Sebald \\
\hline GAI96448 & 58 & Stool & Japan, Gifu & $c e p A, b f t-1$ & $0 \cdot 19$ & N. Kato \\
\hline 20 & 59 & Gynaecological pus & Switzerland, Ticino & cepA & $0 \cdot 064$ & IBS \\
\hline L754 & 60 & Blood & Switzerland, Lausanne & серA & $0 \cdot 064$ & J. Bille \\
\hline 69 & 61 & Bartholinitis & Switzerland, Ticino & $c e p A, b f t-2$ & $0 \cdot 032$ & IBS \\
\hline 123 & 62 & Unknown & Switzerland, Ticino & $\operatorname{cep} A, b f t-2$ & $0 \cdot 064$ & IBS \\
\hline 1208 & 63 & LCR-meningitis & France, Paris & $c e p A, b f t-1$ & $0 \cdot 064$ & M. Sebald \\
\hline 1237 & 64 & Blood & France, Paris & cepA & $0 \cdot 033$ & M. Sebald \\
\hline 59 & 65 & Intestinal tumour & Switzerland, Ticino & cepA & $0 \cdot 19$ & IBS \\
\hline F59G & 66 & Stool from patient 59 & Switzerland, Ticino & cepA & $0 \cdot 50$ & IBS \\
\hline $1077-92$ & 67 & Stool from healthy volunteer & Norway, Bergen & $\operatorname{cep} A, b f t-2$ & $0 \cdot 25$ & T. Hofstad \\
\hline 1269 & 68 & Blood & France, Paris & cepA & $0 \cdot 094$ & M. Sebald \\
\hline $\begin{array}{l}\text { DSM } 1396 \\
(=\text { ATCC } \\
23745)\end{array}$ & 69 & $\begin{array}{l}\text { Reference strain; clinical origin, } \\
\text { pleural fluid }\end{array}$ & Unknown & cepA & $0 \cdot 064$ & DSM \\
\hline 64 & 70 & $\begin{array}{l}\text { Blood (septicaemia after sacral } \\
\text { decubitus) }\end{array}$ & Switzerland, Ticino & cepA, bft-2 & $0 \cdot 38$ & IBS \\
\hline F64D & 71 & Stool from patient 64 & Switzerland, Ticino & $c e p A, b f t-1$ & $0 \cdot 25$ & IBS \\
\hline 120 & 72 & Inguinal abscess & Switzerland, Ticino & серA & $0 \cdot 032$ & IBS \\
\hline F64B & 73 & Stool from patient 64 & Switzerland, Ticino & cepA, bft-2 & $0 \cdot 125$ & IBS \\
\hline F120B & 74 & Stool from patient 120 & Switzerland, Ticino & серA & $0 \cdot 047$ & IBS \\
\hline 96 & 75 & Blood & Switzerland, Ticino & cepA & $0 \cdot 047$ & IBS \\
\hline F64E & 76 & Stool from patient 64 & Switzerland, Ticino & cepA, bft-1 & $0 \cdot 25$ & IBS \\
\hline 135 & 77 & Unknown & Switzerland, Ticino & cepA, bft-1 & $0 \cdot 19$ & IBS \\
\hline 1343 & 78 & Blood & France, Paris & $c e p A, b f t-1$ & $0 \cdot 064$ & M. Sebald \\
\hline L93 & 79 & Blood & Switzerland, Lausanne & серA & $0 \cdot 5$ & J. Bille \\
\hline F70A & 80 & Stool from patient 70 & Switzerland, Ticino & cepA, bft-1 & $0 \cdot 047$ & IBS \\
\hline 25 & 81 & Blood & Switzerland, Ticino & $\operatorname{cepA}$ & $0 \cdot 047$ & IBS \\
\hline \multicolumn{7}{|l|}{ Division II } \\
\hline 1429 & 82 & Eschar & France, Paris & $c f i A$, IS1186 & $>32$ & M. Sebald \\
\hline BFR271R & 83 & Unknown & France, Paris & $c f i A$, IS1186 & $>32$ & E. Collatz \\
\hline BFR81R & 84 & Unknown & France, Paris & cfiA, IS1186 & $>32$ & E. Collatz \\
\hline TAL2480 & 85 & Unknown & United States & $c f i A$, IS942 & $>32$ & $\begin{array}{l}\text { Thompson \& } \\
\text { Malamy } \\
(1990)\end{array}$ \\
\hline TAL3636 & 85 & Unknown & United States & $c f i A$, IS942 & $>32$ & $\begin{array}{l}\text { Thompson \& } \\
\text { Malamy } \\
(1990)\end{array}$ \\
\hline
\end{tabular}


Table 1 (cont.)

\begin{tabular}{|c|c|c|c|c|c|c|}
\hline Isolate & ET & Biological origin & Geographical origin & $\begin{array}{c}\text { Genotypic } \\
\text { characterization }\end{array}$ & $\begin{array}{c}\text { MIC of } \\
\text { imipenem } \\
\left(\mu \mathrm{g} \mathrm{ml}^{-1}\right)\end{array}$ & Source* \\
\hline VPI2393 & 86 & Unknown & France, Paris & $c f i A$ & $3 \cdot 0$ & Johnson (1978) \\
\hline VPI3392 & 87 & Unknown & France, Paris & cfiA & $1 \cdot 5$ & Johnson (1978) \\
\hline 1297 & 88 & Appendicitis pus & France, Paris & $c f i A$ & $1 \cdot 5$ & M. Sebald \\
\hline 28794 & 89 & Blood & Norway, Bergen & cfiA & $4 \cdot 0$ & T. Hofstad \\
\hline 127 & 90 & Unknown & Switzerland, Ticino & cfiA & $1 \cdot 5$ & IBS \\
\hline \multicolumn{7}{|c|}{ Outgroup $\ddagger$} \\
\hline D3433 & 91 & Lung abscess, hamster & Switzerland, Bern & & $0 \cdot 064$ & J. Nicolet \\
\hline ZIB3071 & 92 & Periodontal pocket & Switzerland, Basel & & $0 \cdot 023$ & J. Meyer \\
\hline F120C & 93 & Stool from patient 120 & Switzerland, Ticino & & $0 \cdot 25$ & IBS \\
\hline L138 & 94 & Peritoneal liquid & Switzerland, Lausanne & & $0 \cdot 50$ & J. Bille \\
\hline F120A & 95 & Stool from patient 120 & Switzerland, Ticino & & 0.75 & IBS \\
\hline 23 & 96 & Blood & Switzerland, Ticino & & 0.094 & IBS \\
\hline
\end{tabular}

*IBS, Istituto Cantonale Batteriosierologico, Lugano; R. Zbinden, Institut für medizinische Mikrobiologie Universität Zürich, Zürich, Switzerland; J. Nicolet, Institute for Veterinary Bacteriology, University of Bern, Bern, Switzerland; N. Kato, Institute of Anaerobic Bacteriology, Gifu University School of Medicine, Gifu, Japan; T. Hofstad, Department of Microbiology and Immunology, The Gade Institute, University of Bergen, Bergen, Norway; M. Sebald, Unité des Anaérobies, Institut Pasteur, Paris, France; J. Bille, Laboratoire de bactériologie médicale, CHUV, Lausanne, Switzerland; E. Collatz, LRMA, Université Paris VI, Paris France; J. Meyer, Zahnärtztliches Institut der Universität Basel, Switerzland.

† $b f t-3$ in the table means 'potential $b f t-3$ ', since it probably corresponds to $b f t-3$ described by N. Kato at the 2 nd World Congress of Anaerobic Bacteria and Infections, 1998 (N. Kato, personal communication; Kato et al., 2000).

‡Outgroup strains were: D3433, B. uniformis; ZIB3071, P. gingivalis; F120C, B. ovatus; L138, F120A and 23, B. vulgatus.

DNA extraction and PCR. Samples $(50 \mu \mathrm{l})$ of the bacterial suspensions in water were thawed and DNA was extracted with a commercial ion-exchange resin (InstaGene matrix ; Bio$\mathrm{Rad}$ ) according to the manufacturer's instructions. PCR was performed in a total volume of $50 \mu \mathrm{l}$ containing: $10 \mu \mathrm{l}$ of the DNA extract, $10 \mathrm{mM}$ Tris $/ \mathrm{HCl} \mathrm{pH} 8.3,50 \mathrm{mM} \mathrm{KCl}, 2.5 \mathrm{mM}$ $\mathrm{MgCl}_{2}, 200 \mu \mathrm{M}$ of each dNTP, $0 \cdot 01 \%$ gelatin type A (Sigma), $0.5 \mu \mathrm{M}$ of each primer, and 1 unit Taq polymerase (Boehringer Mannheim); the reactions were overlaid with paraffin oil (Merck) to prevent evaporation.

All 93 B. fragilis strains and also the outgroup strains were subjected to the PCR experiments described hereafter to detect enterotoxin-encoding genes and genes encoding antibiotic resistance. A $294 \mathrm{bp}$ fragment of the $b f t$ gene was amplified by PCR according to Pantosti et al. (1997a) with the primers BF-1 (5'-GACGGTGTATGTGATTTGTCTGAGAGA-3') and BF-2 (5'-ATCCCTAAGATTTTATTATCCCAAGTA-3'). A thermal profile of $94^{\circ} \mathrm{C}$ for $60 \mathrm{~s}, 52^{\circ} \mathrm{C}$ for $60 \mathrm{~s}$ and $72{ }^{\circ} \mathrm{C}$ for $60 \mathrm{~s}$ was repeated for 35 cycles. These primers allowed the amplification of the $b f t-1$ and $b f t-2$ alleles of the enterotoxinencoding gene. To avoid false negative results due to mutations in the primer regions, a second primer pair was developed in our laboratory: BF-3 (5'-GTTAGTGCCCAGATGCAGG-3') and BF-4 (5'-TAGTTCGTGTGCCATCACCC- $\left.3^{\prime}\right)$. To amplify the corresponding $341 \mathrm{bp}$ fragment of $b f t$, a 35 -cycle PCR with the following thermal profile was performed: $94^{\circ} \mathrm{C}$ for $60 \mathrm{~s}, 50^{\circ} \mathrm{C}$ for $60 \mathrm{~s}$ and $72{ }^{\circ} \mathrm{C}$ for $90 \mathrm{~s}$. A third PCR, detecting $b f t-1, b f t-2$ and also the third $b f t$ allele $(b f t-3)$, was performed with primers provided by N. Kato (N. Kato, personal communication; Kato et al., 2000).

Based on DNA sequence alignment of the published cfiA (Khushi et al., 1996; Tally \& Jacobus, 1983; Thompson \&
Malamy, 1990) and cepA (Rasmussen et al., 1990) genes, four primers corresponding to relatively conserved regions of the coding sequences were designed: $c f i A-1$ (5'-ATGGTACCTTCCAACGGG-3') and $c f A-2$ (5'-CACGATATTGTCGGTCGC-3'), and cepA-1 (5'-TTTCTGCTATGTCCTGCCC-3') and cepA-2 (5'-ATCTTTCACGAAGACGGC-3'). The fragment amplified by $c f i-1$ and $c f i A-2$ was 353 bp long. The $c f i A$ PCR consisted of 35 cycles with a thermal profile of $94^{\circ} \mathrm{C}$ for $60 \mathrm{~s}, 56^{\circ} \mathrm{C}$ for $60 \mathrm{~s}$ and $72{ }^{\circ} \mathrm{C}$ for $60 \mathrm{~s}$. Primers cepA-1 and cepA-2 amplified a $780 \mathrm{bp}$ fragment in a PCR of 35 cycles, with the following thermal profile: $94^{\circ} \mathrm{C}$ for $60 \mathrm{~s}, 52^{\circ} \mathrm{C}$ for $60 \mathrm{~s}$ and $72^{\circ} \mathrm{C}$ for $60 \mathrm{~s}$. Furthermore, based on the published sequences (Podglajen et al., 1994; Rasmussen et al., 1990; Thompson \& Malamy, 1990), primers were designed for the insertion sequences IS1186 and IS942. The forward primers were 5'-TCCTCAATACATGAGCCGC-3' for IS942, and 5'-TGACCTACAACATCTTCCG-3' for IS1186. The reverse primer was the same for the detection of both insertion sequences. This primer was designed on position 165-186 of the $c f i A$ gene: $c f i A-3$ (5'-GGTTGTTGATAACAATCATCCC-3'). PCR of 35 cycles was performed using the following conditions: $94^{\circ} \mathrm{C}$ for $60 \mathrm{~s}, 50^{\circ} \mathrm{C}$ for $60 \mathrm{~s}$ and $72{ }^{\circ} \mathrm{C}$ for $90 \mathrm{~s}$.

Isolates showing a genetic distance from other strains higher than 0.60 by MLEE were confirmed to be B. fragilis using $16 \mathrm{~S}$ rRNA amplification and sequencing. 16S rRNA PCR was performed with universal primers UNI16RNA-L (5'-ATTCTAGAGTTTGATCATGGCTCA-3'; E. coli coordinates 326) and UNI16RNA-R (5'-ATGGTACCGTGTGACGGGCGGTGTGTA-3'; E. coli coordinates 1419-1393), amplifying a product of roughly $1400 \mathrm{bp}$ (a kind gift from J. Frey, University of Bern). The thermal profile consisted of 35 cycles of $94{ }^{\circ} \mathrm{C}$ for $30 \mathrm{~s}, 52{ }^{\circ} \mathrm{C}$ for $30 \mathrm{~s}$ and $72{ }^{\circ} \mathrm{C}$ for $60 \mathrm{~s}$. The PCR 
Table 2. Allelic profile at 15 enzyme loci for 93 B. fragilis isolates

\begin{tabular}{|c|c|c|c|c|c|c|c|c|c|c|c|c|c|c|c|}
\hline \multirow[t]{2}{*}{ ET } & \multicolumn{15}{|c|}{ No. of alleles at the following enzyme loci: } \\
\hline & NSP & PGI & GDA & GD1 & HEX & G6P & $\mathrm{MDH}$ & PGM & $\alpha \mathrm{GAL}$ & $\alpha$ GLUS & EST & IPO & $\mathrm{AF}$ & FP & CAT \\
\hline 1 & 2 & 4 & 5 & 2 & 5 & 5 & 4 & 6 & 3 & 5 & 4 & 3 & 7 & 1 & 5 \\
\hline 2 & 2 & 4 & 5 & 2 & 5 & 5 & 4 & 6 & 3 & 4 & 4 & 3 & 7 & 1 & 5 \\
\hline 3 & 2 & 4 & 5 & 2 & 5 & 5 & 4 & 6 & 3 & 3 & 4 & 3 & 7 & 2 & 5 \\
\hline 4 & 2 & 4 & 5 & 2 & 5 & 5 & 4 & 6 & 0 & 5 & 4 & 3 & 7 & 2 & 5 \\
\hline 5 & 2 & 4 & 5 & 2 & 5 & 5 & 4 & 6 & 5 & 3 & 4 & 3 & 7 & 5 & 5 \\
\hline 6 & 2 & 4 & 6 & 2 & 5 & 5 & 4 & 6 & 3 & 5 & 4 & 3 & 7 & 2 & 5 \\
\hline 7 & 2 & 4 & 6 & 2 & 5 & 5 & 4 & 6 & 3 & 4 & 4 & 3 & 7 & 2 & 5 \\
\hline 8 & 2 & 4 & 6 & 2 & 5 & 5 & 4 & 6 & 3 & 8 & 4 & 3 & 7 & 17 & 5 \\
\hline 9 & 2 & 4 & 6 & 2 & 5 & 4 & 4 & 6 & 3 & 5 & 4 & 3 & 7 & 2 & 5 \\
\hline 10 & 2 & 4 & 6 & 2 & 5 & 7 & 4 & 6 & 3 & 3 & 4 & 3 & 7 & 1 & 5 \\
\hline 11 & 2 & 4 & 6 & 2 & 5 & 5 & 4 & 6 & 2 & 3 & 4 & 3 & 7 & 1 & 5 \\
\hline 12 & 2 & 4 & 6 & 2 & 5 & 5 & 4 & 6 & 3 & 6 & 4 & 3 & 6 & 1 & 5 \\
\hline 13 & 2 & 4 & 6 & 2 & 5 & 5 & 4 & 6 & 3 & 4 & 4 & 3 & 6 & 1 & 5 \\
\hline 14 & 2 & 4 & 6 & 2 & 5 & 5 & 4 & 6 & 3 & 6 & 4 & 3 & 6 & 3 & 5 \\
\hline 15 & 2 & 4 & 6 & 2 & 5 & 5 & 4 & 6 & 3 & 4 & 4 & 3 & 6 & 18 & 5 \\
\hline 16 & 2 & 4 & 6 & 2 & 5 & 5 & 4 & 6 & 3 & 5 & 4 & 3 & 6 & 2 & 5 \\
\hline 17 & 2 & 4 & 6 & 2 & 5 & 5 & 4 & 6 & 3 & 9 & 4 & 3 & 6 & 2 & 5 \\
\hline 18 & 2 & 4 & 6 & 2 & 5 & 5 & 4 & 6 & 3 & 8 & 4 & 3 & 6 & 5 & 5 \\
\hline 19 & 2 & 4 & 6 & 2 & 5 & 5 & 4 & 6 & 7 & 6 & 4 & 3 & 6 & 8 & 5 \\
\hline 20 & 2 & 4 & 5 & 2 & 5 & 5 & 4 & 6 & 10 & 1 & 4 & 3 & 6 & 11 & 5 \\
\hline 21 & 2 & 4 & 6 & 2 & 5 & 5 & 4 & 6 & 5 & 6 & 4 & 4 & 6 & 1 & 5 \\
\hline 22 & 2 & 4 & 6 & 2 & 5 & 5 & 4 & 6 & 5 & 6 & 4 & 3 & 7 & 3 & 5 \\
\hline 23 & 2 & 4 & 6 & 2 & 5 & 5 & 4 & 6 & 8 & 2 & 4 & 3 & 0 & 11 & 5 \\
\hline 24 & 2 & 4 & 6 & 5 & 5 & 5 & 4 & 6 & 3 & 7 & 4 & 3 & 0 & 2 & 5 \\
\hline 25 & 2 & 4 & 6 & 5 & 5 & 5 & 4 & 6 & 3 & 7 & 4 & 3 & 6 & 2 & 5 \\
\hline 26 & 2 & 4 & 6 & 5 & 5 & 5 & 4 & 6 & 3 & 5 & 4 & 3 & 7 & 1 & 5 \\
\hline 27 & 2 & 4 & 6 & 6 & 5 & 5 & 4 & 6 & 10 & 2 & 4 & 3 & 7 & 11 & 5 \\
\hline 28 & 2 & 4 & 6 & 2 & 5 & 6 & 4 & 7 & 3 & 5 & 4 & 3 & 7 & 1 & 5 \\
\hline 29 & 2 & 4 & 6 & 2 & 5 & 5 & 4 & 7 & 3 & 5 & 4 & 3 & 7 & 1 & 5 \\
\hline 30 & 2 & 4 & 6 & 2 & 5 & 6 & 4 & 6 & 10 & 4 & 4 & 3 & 1 & 6 & 5 \\
\hline 31 & 2 & 4 & 6 & 2 & 5 & 6 & 4 & 6 & 3 & 3 & 4 & 3 & 1 & 2 & 5 \\
\hline 32 & 2 & 4 & 6 & 2 & 5 & 5 & 2 & 6 & 5 & 3 & 4 & 3 & 6 & 1 & 5 \\
\hline 33 & 2 & 4 & 6 & 2 & 5 & 5 & 2 & 6 & 5 & 3 & 4 & 3 & 6 & 2 & 5 \\
\hline 34 & 2 & 4 & 6 & 2 & 5 & 5 & 2 & 6 & 5 & 3 & 4 & 3 & 6 & 5 & 5 \\
\hline 35 & 2 & 4 & 6 & 2 & 5 & 5 & 2 & 6 & 5 & 4 & 4 & 3 & 6 & 9 & 5 \\
\hline 36 & 2 & 4 & 6 & 2 & 5 & 5 & 2 & 6 & 3 & 7 & 4 & 3 & 6 & 5 & 5 \\
\hline 37 & 2 & 4 & 6 & 2 & 5 & 5 & 2 & 6 & 3 & 3 & 4 & 3 & 6 & 5 & 5 \\
\hline 38 & 2 & 4 & 6 & 2 & 5 & 5 & 3 & 6 & 3 & 1 & 4 & 3 & 6 & 5 & 5 \\
\hline 39 & 2 & 4 & 6 & 2 & 5 & 5 & 3 & 6 & 3 & 3 & 4 & 3 & 6 & 2 & 5 \\
\hline 40 & 2 & 4 & 6 & 2 & 5 & 6 & 4 & 6 & 3 & 4 & 4 & 3 & 6 & 1 & 5 \\
\hline 41 & 2 & 4 & 6 & 2 & 5 & 3 & 4 & 6 & 3 & 7 & 4 & 3 & 6 & 1 & 5 \\
\hline 42 & 2 & 4 & 6 & 2 & 5 & 9 & 4 & 6 & 3 & 4 & 4 & 3 & 6 & 2 & 5 \\
\hline 43 & 2 & 4 & 6 & 2 & 5 & 7 & 2 & 6 & 3 & 9 & 4 & 3 & 6 & 1 & 5 \\
\hline 44 & 2 & 4 & 6 & 2 & 5 & 6 & 2 & 6 & 3 & 4 & 4 & 3 & 6 & 14 & 5 \\
\hline 45 & 2 & 4 & 6 & 2 & 4 & 5 & 4 & 6 & 3 & 6 & 4 & 3 & 6 & 2 & 5 \\
\hline 46 & 2 & 4 & 6 & 2 & 0 & 5 & 4 & 6 & 3 & 4 & 4 & 3 & 6 & 1 & 5 \\
\hline 47 & 2 & 4 & 6 & 2 & 5 & 5 & 4 & 6 & 3 & 4 & 4 & 3 & 7 & 2 & 4 \\
\hline 48 & 2 & 4 & 6 & 2 & 5 & 5 & 4 & 6 & 3 & 3 & 4 & 3 & 7 & 2 & 4 \\
\hline 49 & 2 & 4 & 6 & 2 & 5 & 5 & 4 & 6 & 4 & 3 & 4 & 3 & 6 & 14 & 4 \\
\hline 50 & 2 & 4 & 6 & 2 & 5 & 5 & 4 & 6 & 3 & 3 & 4 & 3 & 0 & 2 & 6 \\
\hline
\end{tabular}


Table 2 (cont.)

\begin{tabular}{|c|c|c|c|c|c|c|c|c|c|c|c|c|c|c|c|}
\hline \multirow[t]{2}{*}{ ET } & \multicolumn{15}{|c|}{ No. of alleles at the following enzyme loci: } \\
\hline & NSP & PGI & GDA & GD1 & HEX & G6P & MDH & PGM & $\alpha \mathrm{GAL}$ & $\alpha$ GLUS & EST & IPO & $\mathrm{AF}$ & FP & CAT \\
\hline 51 & 2 & 4 & 5 & 2 & 5 & 8 & 4 & 6 & 3 & 6 & 4 & 3 & 6 & 2 & 5 \\
\hline 52 & 2 & 4 & 5 & 2 & 5 & 3 & 4 & 6 & 3 & 7 & 4 & 3 & 6 & 2 & 5 \\
\hline 53 & 2 & 4 & 5 & 2 & 5 & 5 & 4 & 6 & 3 & 2 & 4 & 3 & 6 & 2 & 5 \\
\hline 54 & 2 & 4 & 5 & 2 & 5 & 5 & 4 & 6 & 3 & 7 & 4 & 3 & 6 & 2 & 5 \\
\hline 55 & 2 & 4 & 5 & 2 & 5 & 5 & 4 & 6 & 3 & 11 & 4 & 3 & 6 & 2 & 5 \\
\hline 56 & 2 & 4 & 5 & 2 & 5 & 5 & 4 & 6 & 3 & 4 & 4 & 3 & 6 & 1 & 5 \\
\hline 57 & 2 & 4 & 5 & 2 & 5 & 5 & 4 & 6 & 3 & 4 & 4 & 3 & 6 & 12 & 5 \\
\hline 58 & 2 & 4 & 5 & 2 & 5 & 5 & 4 & 6 & 3 & 4 & 4 & 3 & 9 & 1 & 5 \\
\hline 59 & 2 & 4 & 5 & 2 & 5 & 6 & 4 & 6 & 6 & 6 & 4 & 3 & 6 & 1 & 5 \\
\hline 60 & 2 & 4 & 5 & 2 & 5 & 5 & 4 & 2 & 4 & 6 & 4 & 3 & 6 & 2 & 5 \\
\hline 61 & 2 & 4 & 5 & 2 & 5 & 6 & 3 & 2 & 3 & 5 & 4 & 3 & 1 & 2 & 5 \\
\hline 62 & 2 & 4 & 5 & 2 & 5 & 5 & 3 & 2 & 5 & 4 & 4 & 3 & 1 & 2 & 5 \\
\hline 63 & 2 & 4 & 5 & 2 & 5 & 5 & 3 & 6 & 3 & 4 & 4 & 3 & 1 & 1 & 5 \\
\hline 64 & 2 & 4 & 5 & 2 & 5 & 2 & 3 & 6 & 5 & 7 & 4 & 3 & 6 & 2 & 5 \\
\hline 65 & 2 & 4 & 6 & 2 & 5 & 5 & 4 & 2 & 3 & 5 & 2 & 3 & 6 & 12 & 5 \\
\hline 66 & 2 & 4 & 6 & 2 & 5 & 5 & 4 & 2 & 3 & 5 & 2 & 3 & 6 & 2 & 5 \\
\hline 67 & 2 & 4 & 6 & 2 & 5 & 5 & 4 & 6 & 5 & 6 & 2 & 3 & 6 & 7 & 5 \\
\hline 68 & 2 & 4 & 6 & 2 & 5 & 5 & 4 & 6 & 3 & 6 & 2 & 3 & 6 & 2 & 5 \\
\hline 69 & 2 & 4 & 5 & 2 & 5 & 5 & 4 & 6 & 4 & 6 & 2 & 3 & 6 & 1 & 5 \\
\hline 70 & 2 & 4 & 6 & 2 & 5 & 7 & 4 & 6 & 3 & 5 & 4 & 4 & 6 & 1 & 5 \\
\hline 71 & 2 & 4 & 6 & 2 & 5 & 6 & 4 & 6 & 3 & 5 & 4 & 4 & 6 & 1 & 5 \\
\hline 72 & 2 & 4 & 6 & 2 & 5 & 5 & 4 & 6 & 3 & 5 & 4 & 4 & 6 & 1 & 5 \\
\hline 73 & 2 & 4 & 6 & 2 & 5 & 5 & 4 & 6 & 3 & 1 & 4 & 4 & 6 & 1 & 5 \\
\hline 74 & 2 & 4 & 6 & 8 & 5 & 5 & 4 & 6 & 5 & 6 & 3 & 3 & 7 & 3 & 5 \\
\hline 75 & 2 & 4 & 6 & 2 & 5 & 5 & 4 & 6 & 6 & 6 & 4 & 4 & 6 & 2 & 5 \\
\hline 76 & 2 & 4 & 6 & 2 & 5 & 6 & 4 & 6 & 3 & 1 & 3 & 4 & 6 & 1 & 5 \\
\hline 77 & 2 & 4 & 6 & 7 & 5 & 5 & 2 & 6 & 5 & 3 & 4 & 3 & 6 & 1 & 5 \\
\hline 78 & 2 & 0 & 6 & 2 & 5 & 5 & 2 & 6 & 5 & 3 & 4 & 3 & 6 & 0 & 5 \\
\hline 79 & 2 & 4 & 6 & 7 & 5 & 5 & 5 & 6 & 10 & 1 & 4 & 3 & 8 & 11 & 5 \\
\hline 80 & 2 & 4 & 6 & 8 & 5 & 5 & 4 & 6 & 5 & 6 & 3 & 3 & 7 & 3 & 5 \\
\hline 81 & 2 & 4 & 5 & 2 & 5 & 7 & 3 & 6 & 5 & 4 & 2 & 3 & 7 & 5 & 5 \\
\hline 82 & 2 & 2 & 6 & 6 & 2 & 9 & 10 & 2 & 10 & 4 & 6 & 3 & 6 & 9 & 1 \\
\hline 83 & 2 & 2 & 6 & 6 & 2 & 9 & 10 & 5 & 10 & 4 & 6 & 3 & 6 & 9 & 1 \\
\hline 84 & 2 & 2 & 6 & 6 & 2 & 9 & 10 & 1 & 10 & 4 & 6 & 3 & 6 & 9 & 1 \\
\hline 85 & 2 & 2 & 4 & 6 & 2 & 9 & 10 & 5 & 10 & 4 & 6 & 3 & 6 & 4 & 1 \\
\hline 86 & 2 & 2 & 6 & 6 & 2 & 5 & 10 & 4 & 10 & 3 & 6 & 3 & 6 & 4 & 1 \\
\hline 87 & 2 & 4 & 5 & 4 & 2 & 5 & 10 & 5 & 10 & 3 & 6 & 3 & 7 & 4 & 1 \\
\hline 88 & 2 & 2 & 4 & 6 & 5 & 9 & 10 & 2 & 10 & 4 & 6 & 3 & 6 & 9 & 1 \\
\hline 89 & 2 & 2 & 4 & 3 & 2 & 9 & 10 & 4 & 2 & 4 & 4 & 3 & 7 & 4 & 1 \\
\hline 90 & 2 & 4 & 6 & 2 & 1 & 9 & 10 & 5 & 10 & 0 & 6 & 3 & 9 & 13 & 3 \\
\hline 91 & 3 & 1 & 0 & 3 & 0 & 11 & 4 & 1 & 10 & 4 & 9 & 1 & 3 & 1 & 5 \\
\hline 92 & 5 & 7 & 0 & 1 & 0 & 0 & 1 & 0 & 0 & 0 & 9 & 1 & 4 & 16 & 5 \\
\hline 93 & 1 & 2 & 2 & 10 & 1 & 12 & 9 & 4 & 0 & 0 & 8 & 7 & 5 & 10 & 5 \\
\hline 94 & 4 & 5 & 1 & 4 & 0 & 1 & 7 & 9 & 9 & 10 & 7 & 6 & 2 & 6 & 0 \\
\hline 95 & 4 & 6 & 1 & 4 & 0 & 1 & 7 & 9 & 11 & 10 & 7 & 6 & 2 & 6 & 0 \\
\hline 96 & 4 & 5 & 1 & 0 & 0 & 1 & 7 & 9 & 11 & 10 & 7 & 5 & 2 & 6 & 0 \\
\hline
\end{tabular}

product was identified as $B$. fragilis $16 \mathrm{~S}$ rRNA by a BLAST sequence similarity search in GenBank.

DNA sequencing and alignment. PCR products for direct sequencing were prepared with the QIAquick PCR Purification Kit (Qiagen) and sequenced with the ABI Prism dRhodamine dye terminator Cycle Sequencing Ready Re- action Kit (dRhodamine terminator; Perkin-Elmer Applied Biosystems).

Sequence data were analysed by pairwise sequence alignment and by multi-alignment with the Lasergene program Megalign (DNASTAR). Phylogenetic analysis was performed using MEGA (Molecular Evolutionary Genetics Analysis 1.01; Kumar et al., 1993). 


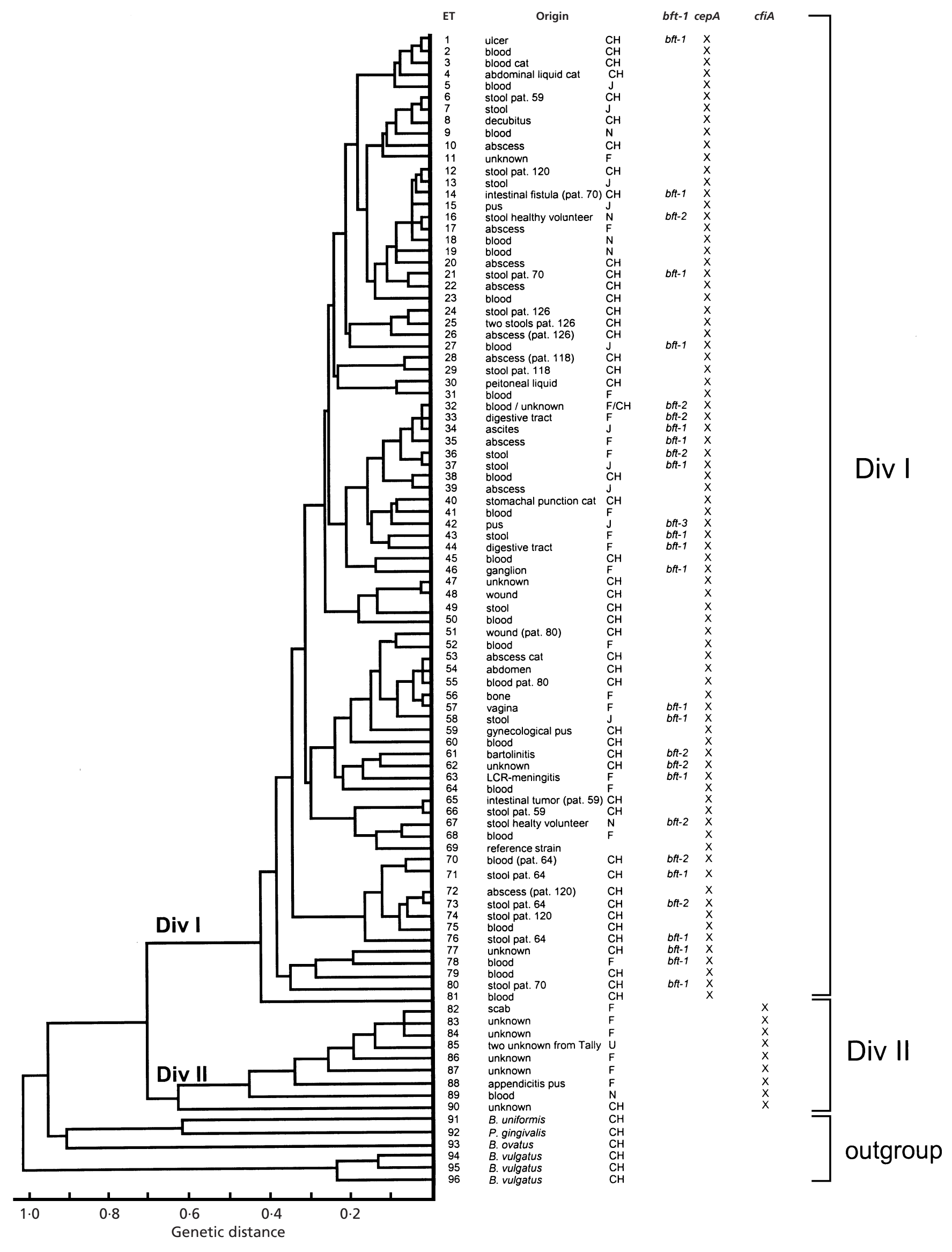


The DNA sequences determined in this work are in the GenBank/EMBL/DDBJ databases under accession numbers AF197508-AF197534.

Statistical analysis. Statistical analysis of the MLEE data was performed using a computer program designed by Whittam et al. (1983). Briefly, the genetic diversity $(b)$ for each enzyme locus among ETs was calculated as $h=\left(1-\Sigma x_{i}^{2}\right)[n /(n-1)]$, where $x_{i}$ is the frequency of the $i$ th allele and $n$ is the number of ETs. The genetic distance between ETs was expressed as the proportion of loci at which dissimilar alleles occurred, with the contribution of each locus inversely weighted by the genetic diversity $(b)$ at the locus. The ET clustering and the generation of a dendrogram according to genetic distances were determined with the average-linkage method from a matrix of coefficients of pairwise genetic distances (Selander et al., 1986). Variance comparison of the distribution of allele mismatches was done by method B of Brown et al. (1980).

\section{RESULTS}

\section{Genetic and genotypic diversity}

Fourteen of the 15 enzymes analysed in the population of $93 \mathrm{~B}$. fragilis isolates were polymorphic. The exception was NSP, which was monomorphic. The mean number of alleles per locus varied from 1 (NSP) to 16 (FP), with an overall mean of 6 (see Table 3). Genetic diversities among ETs at each locus ranged from 0 (NSP) to $0.805(\mathrm{FP})$, with a mean genetic diversity per locus of 0.393 (Table 3). The 93 B. fragilis strains presented 90 distinct ETs (Tables 1 and 2). The Bacteroides strains that were not $B$. fragilis ( $3 \mathrm{~B}$. vulgatus, $1 \mathrm{~B}$. ovatus, $1 \mathrm{~B}$. uniformis), and the $P$. gingivalis strain, had very distinct allele profiles (Table 2). The five bacterial species studied presented clearly distinct NSP electromorphs.

\section{Genetic relationships among ETs}

Cluster analysis of the 90 ETs of $B$. fragilis by the average-linkage method identified two major divisions separated at a genetic distance of $0 \cdot 70$ (Fig. 1). Division I consisted of 81 ETs (83 strains) and division II consisted of 9 ETs (10 strains). The mean genetic diversity per locus of ETs in divisions I and II was 0.314 and 0.356 , respectively (Table 3 ). Division-specific alleles were found for ten enzyme loci (CAT, $\alpha$ GLUS, EST, HEX, IPO, GDA, FP, PGM, MDH, PGI; Table 2).

16S rRNA sequencing combined with a BLAST sequence similarity search in GenBank confirmed that isolates corresponding to ETs 89 and 90 really were $B$. fragilis: $97-99 \%$ similarities with other $B$. fragilis $16 \mathrm{~S} \mathrm{rRNA}$ present in the database were observed for both isolates. These isolates were analysed because of their high genetic distances (higher than 0.60 ) from ETs of other $B$. fragilis isolates of division II.
Table 3. Number of alleles and genetic diversity per enzyme locus for 93 B. fragilis isolates

\begin{tabular}{|c|c|c|c|c|}
\hline \multirow{2}{*}{$\begin{array}{l}\text { Enzyme } \\
\text { locus }\end{array}$} & \multirow{2}{*}{$\begin{array}{l}\text { No. of } \\
\text { alleles }\end{array}$} & \multicolumn{3}{|c|}{$\boldsymbol{h}$ (genetic diversity per locus) } \\
\hline & & Div. I & Div. II & Total \\
\hline NSP & 1 & $0 \cdot 000$ & $0 \cdot 000$ & $0 \cdot 000$ \\
\hline PGI & 3 & $0 \cdot 025$ & $0 \cdot 389$ & $0 \cdot 166$ \\
\hline GDA & 3 & $0 \cdot 389$ & $0 \cdot 639$ & $0 \cdot 427$ \\
\hline GD1 & 6 & $0 \cdot 165$ & $0 \cdot 417$ & $0 \cdot 299$ \\
\hline HEX & 5 & $0 \cdot 049$ & $0 \cdot 417$ & $0 \cdot 206$ \\
\hline G6P & 8 & $0 \cdot 403$ & $0 \cdot 389$ & $0 \cdot 479$ \\
\hline $\mathrm{MDH}$ & 5 & $0 \cdot 377$ & $0 \cdot 000$ & $0 \cdot 487$ \\
\hline PGM & 6 & $0 \cdot 163$ & $0 \cdot 778$ & $0 \cdot 318$ \\
\hline$\alpha \mathrm{GAL}$ & 9 & 0.539 & $0 \cdot 222$ & $0 \cdot 612$ \\
\hline$\alpha$ GLUS & 11 & $0 \cdot 854$ & $0 \cdot 556$ & $0 \cdot 845$ \\
\hline EST & 4 & $0 \cdot 184$ & $0 \cdot 222$ & $0 \cdot 315$ \\
\hline IPO & 2 & $0 \cdot 160$ & 0.000 & $0 \cdot 145$ \\
\hline $\mathrm{AF}$ & 6 & 0.544 & $0 \cdot 417$ & 0.531 \\
\hline FP & 16 & 0.764 & 0.667 & 0.805 \\
\hline CAT & 5 & $0 \cdot 096$ & $0 \cdot 222$ & $0 \cdot 262$ \\
\hline Mean & 6 & $0 \cdot 314$ & $0 \cdot 356$ & 0.393 \\
\hline
\end{tabular}

\section{Population structure and $\beta$-lactam resistance}

All B. fragilis strains of division I had the gene cepA but not $c f A$, whereas the division II organisms had only the $c f i A$ gene. Division I included a strain (AIP638) previously described as belonging to the cepA-positive/ cfiA-negative group (Ruimy et al., 1996), whereas division II comprised different strains from the DNA homology group II and the $c f i A$-positive/cepA-negative group (VPI2393, VPI3392, TAL3636, Bfr81R, Bfr 271, TAL2480; Johnson, 1978; Podglajen et al., 1995; Ruimy et al., 1996).

Five of the ten isolates of division II expressed imipenem resistance (MICs $\geqslant 32 \mu \mathrm{g} \mathrm{ml}^{-1}$ ), the other five isolates of division II, and all the isolates of division I, were susceptible to this antibiotic (Table 1). In division II, the five isolates expressing the resistance contained either IS1186 or IS942, whereas the other five susceptible isolates did not contain either insertion sequence (Table $1)$.

\section{Source of the isolates}

The human strains analysed were isolated from patients with different clinical manifestations (Table 1). No

Fig. 1. Genetic relationships among $93 B$. fragilis strains, five strains of other Bacteroides species ( $B$. ovatus, $B$. uniformis and $B$. vulgatus) and one $P$. gingivalis strain, based on electrophoretically demonstrable allelic variations at 15 enzyme loci. The dendrogram was generated by using the average-linkage method of clustering and a matrix of pairwise coefficients of genetic distance. Presence of the cepA and the cfiA gene was assessed by PCR (indicated by $\times$ in the figure). The presence of three alleles of $b f t$ (indicated by bft-1, bft- 2 and $b f t-3$ in the figure) was assessed by PCR. Lack of a category for a given marker ( $b f t, c e p A$ or $c f i A)$ indicates that it was not present. Capital letters near the clinical origin of the isolates indicate their geographical origin $(\mathrm{CH}$, Switzerland; F, France; J, Japan; N, Norway). Isolates coming from the same patient (pat.) are indicated by the patient's number beside their origin. 


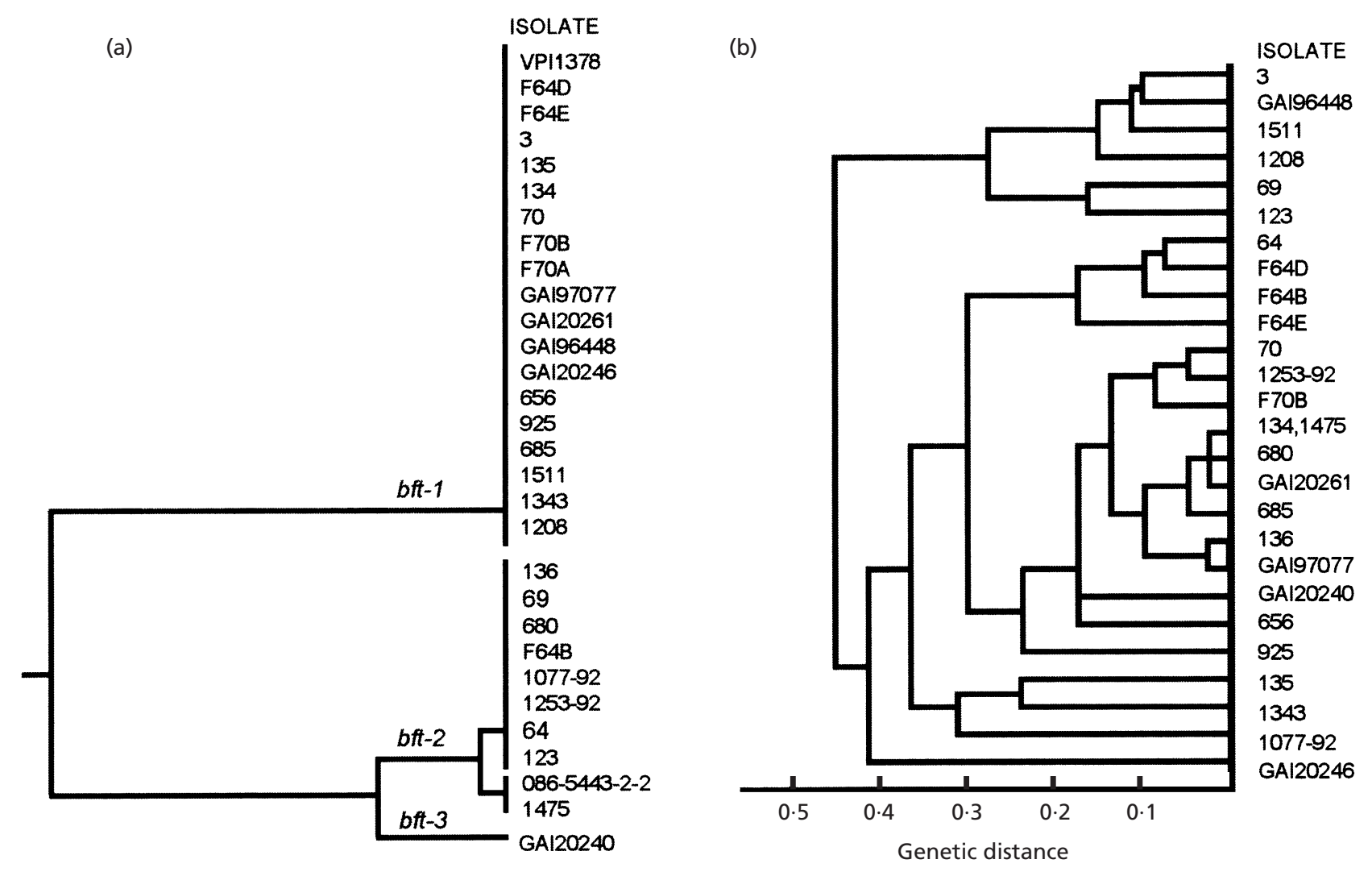

Fig. 2. Distribution of ETBF. (a) Dendrogram generated by the CLUSTAL method, based on the alignment of $189 \mathrm{bp}$ of the $B$. fragilis enterotoxin-encoding gene. Three clusters corresponding to the alleles bft-1, bft-2 and bft-3 were observed. Sequence 086-5443-2-2 (GenBank accession number U90931; Franco et al., 1997) was included in the analysis to show which group was bft-2. (b) Dendrogram including only ETBF, generated by MLEE.

particular cluster was uniquely associated with specific presentations (Fig. 1). For example, the 23 B. fragilis cultured from blood were assigned to ETs in both divisions I and II. A separate analysis of these strains showed a genetic diversity of $0 \cdot 371$, comparable to that of the whole B. fragilis population studied (data not shown).

Faecal isolates were examined from six patients from whom clinical isolates were obtained (Table 1): these faecal isolates all clustered in division I but they did not always belong to the same ET as the invasive strains isolated from the same patient.

Isolates obtained from Norway, Japan, Europe and the United States were not represented by distinct ETs or clusters of ETs, and were distributed throughout the population (Fig. 1).

ETs representing the four animal strains included in this study did not form a separate cluster and were randomly distributed among the ETs representing the human strains.

\section{Distribution of enterotoxigenic $B$. fragilis}

Of the 93 B. fragilis strains investigated, 29 were identified as ETBF by PCR assays targeting the $b f t$ gene. The first PCR used for this gene (primers $B F-1 / B F-2$;
Pantosti et al., 1997a) detected $b f t-1$ and $b f t-2$. The second PCR used here (primers BF-3/BF-4) detected one additional $b f t$ allele $(b f t-3)$. This observation was supported by a third PCR with primers obtained from N. Kato, which detect $b f t-1, b f t-2$ and $b f t-3$. Strains of all the ETs in division II lacked the $b f t$ gene, whereas genotypes carrying the enterotoxin gene were widely distributed in division I (Fig. 1). A common sequence of $189 \mathrm{bp}$ present in all the amplicons generated by the three pairs of primers used was aligned and compared. Sequence alignment showed two ETBF subgroups characterized by either the $b f t-1$ or the $b f t-2$ gene described by Franco et al. (1997; Fig. 2a), and a single isolate (GAI 20240, originating from Japan) with a different $b f t$ sequence. We aligned this $b f t$ sequence with $b f t-3$ from N. Kato (GenBank accession no. AB026624) and with bft-Korea (Chung et al., 1999) and discovered that these three sequences were identical. No apparent association between the presence of one of the $b f t$ alleles and specific clinical manifestation was observed. Furthermore, from the patient presenting the invasive isolate 64, three faecal isolates were obtained: isolates F64D and F64E carried $b f t-1$, and isolates 64 and F64B carried $b f t-2$.

All the sequences of $b f t-1$ were identical (Fig. 2a). In the $b f t-2$ group all the sequences except one were also 
identical with one another but different from $b f t-1$. The exception was the sequence of isolate 1475 (ET 32), which had a difference at two bases compared to the other $294 \mathrm{bp} b f t$-2 amplicons: this sequence was however identical to that published by Franco et al. (1997). The $294 \mathrm{bp}$ amplicons of the $b f t-1$ and $b f t-2$ alleles obtained with primers $B F-1 / B F-2$ differed at 14 nucleotides, 7 of which resulted in amino acid replacements (data not shown). Based on the $189 \mathrm{bp}$ sequenced from the $341 \mathrm{bp}$ amplicon obtained with primers $B F-3$ and $B F-4,20$ point mutations were observed between $b f t-1$ and the potential $b f t-3$, and 8 point mutations between $b f t-2$ and the potential $b f t-3$. The presence of the three $b f t$ alleles could not be associated with any specific genomic cluster evidenced by MLEE (Figs 1 and 2b).

\section{Gene linkage disequilibrium}

Linkage disequilibrium (nonrandom association of alleles over chromosomal loci) was tested by the method of Whittam et al. (1983). The ratio of the observed variance of allele mismatches over the 15 loci to the variance expected in the case of random distribution of alleles was 3.050 for the whole $B$. fragilis population, and 1.079 and 3.384 for divisions I and II, respectively.

\section{DISCUSSION}

\section{Genetic structure of the $B$. fragilis population: two main divisions}

Using MLEE, 93 isolates of $B$. fragilis analysed at 15 enzyme loci were assigned to 90 ETs distributed into two primary genomic divisions (divisions I and II) separated at a genetic distance of $0 \cdot 70$ (Fig. 1 ). The ETs of the B. vulgatus, B. ovatus, B. uniformis and $P$. gingivalis isolates included in this study were clearly separated at genetic distances greater than 0.9 from the $B$. fragilis genotypes, thus confirming their identity as distinct species and the validity of the MLEE method in delineating distant genomic groups. ETs 89 and 90 were separated at a higher genetic distance (higher than 0.62) from the other ETs of division II. Since a genetic distance of 0.7 is suggestive of a new genospecies, $16 \mathrm{~S}$ rRNA sequencing was performed on these isolates, confirming that they were indeed $B$. fragilis.

Using a PCR assay developed in our laboratory, the 83 strains of division I were shown to contain the cepA gene (encoding an Ambler's class A $\beta$-lactamase) but not $c f i A$ (encoding an Ambler's class B $\beta$-lactamase), whereas the 10 strains of division II contained the cfiA gene but not cepA. After exclusion of the strains obtained from laboratories specifically studying these genes, the proportion of isolates encoding $c f i A$ was similar to the proportion of DNA homology group II strains obtained in previous studies (Johnson, 1978). cepA and cfiA have been shown to be related to DNA homology groups I and II, respectively (Ruimy et al., 1996). The finding in our division II of two strains of the DNA homology group II (Table 1), including the type strain (VPI2393; Johnson, 1978), and of isolate 28794, a strain with a ribotype profile similar to that of VPI2393 (Kleivdal \& Hofstad, 1995), strongly suggests that this division corresponds to the DNA homology group II described by Johnson (1978).

Thus, our results delineate two major subdivisions within the species $B$. fragilis - one associated with the $c f i A$ gene and the other, more heterogeneous, with the cepA gene - and are in agreement with those obtained by DNA-DNA hybridization (Johnson, 1978), ribotyping (Kleivdal \& Hofstad, 1995; Smith \& Callihan, 1992; Leszkzynski et al., 1997), AP-PCR (Moraes et al., 1999), insertion sequence content (Podglajen et al., 1995) as well as $16 \mathrm{~S}$ rRNA sequence alignment (Ruimy et al., 1996).

\section{Genetic structure of divisions I and II}

The genetic diversity observed in the $B$. fragilis sample $(0.393)$ was comparable to the genetic diversity observed in many other bacterial populations (Smith \& Callihan, 1992; Go et al., 1996; Selander et al., 1986; Boerlin et al., 1991, 1992; Boerlin \& Piffaretti, 1995). This value and the ratio of the observed to the expected variance $(3 \cdot 050)$ suggest a nonrandom association of the alleles over the chromosome and thus a clonal structure over the whole population. However, the two divisions considered separately show important differences.

Division I presented a large number of ETs separated by low genetic distances $(0 \cdot 018-0 \cdot 401)$ and a genetic diversity of $0 \cdot 314$. The ratio of the observed to the expected variances of division I was close to one (1.079), suggesting a random association of the genes over the chromosome. The lack of linkage disequilibrium (nonrandom association of the alleles over the chromosome) suggests a higher recombination rate, and thus a nonclonal structure of the $B$. fragilis population in division I. This hypothesis is supported by the observation that isolates from different geographical regions did not share the same genotype (with only one exception, ET 32 representing isolate 1475, from Paris, and isolate 134, from Switzerland). Furthermore, in the same geographical region, all isolates belonged to different ETs, supporting the hypothesis of a high recombination rate. Such a high recombination rate is in agreement with the observed heterogeneity of capsular polysaccharides in B. fragilis (Pantosti et al., 1995).

In contrast, division II presented a different population structure, with a high value of the ratio of the variances (3.384), suggesting a lower recombination rate.

Podglajen et al. (1995) proposed that B. fragilis strains carrying cfiA form a novel species. These authors observed heterogeneous ribotype profiles in the cepApositive group and highly homogeneous profiles in the cfiA-positive group. The two divisions observed here also showed a different population structure, with a nonclonal evolution in division $\mathrm{I}$ and a rather clonal evolution in division II. The genetic distance of $0 \cdot 6-0 \cdot 7$, which is empirically considered to be the limit differentiating two species (Boerlin et al., 1991), further 
supports the hypothesis of the presence of two genospecies. Moreover, the MLEE data are consistent with previous DNA-DNA hybridization data, suggesting the existence of two genospecies: Johnson (1978) indeed observed a DNA relatedness of $65-70 \%$ between the two DNA homology groups and a $\Delta T_{\mathrm{m}}$ ranging from $7 \cdot 2$ to $9.5^{\circ} \mathrm{C}$ (Johnson, 1978). A DNA relatedness of less than $70 \%$ and a $\Delta T_{\mathrm{m}}$ of more than $5{ }^{\circ} \mathrm{C}$ is normally considered as the threshold to distinguish bacterial species. Since DNA-DNA hybridization is the reference technique used for species delineation (Wayne et al., 1987, 1996), this method should be performed on our populations to confirm that the $c f i A$ subgroup corresponds to a different genospecies.

\section{Degree of expression of the cfiA gene}

The susceptibility assays of the strains of division II to the antibiotic imipenem showed that the gene was expressed and conferred resistance (MIC $>32 \mu \mathrm{g} \mathrm{ml}^{-1}$; Table 1) in five isolates carrying cfiA. These five resistant isolates formed a closely related cluster of strains (ETs 82-85) within division II. Furthermore, all isolates expressing the imipenem resistance contained at least one insertion sequence (IS1186 or IS942; Table 1), whereas the isolates not expressing the resistance did not contain such insertion sequences. These results are in agreement with those of Podglajen et al. (1995), showing that imipenem susceptibility in division II is not due to the lack of the $c f i A$ gene but to the absence of a precise insertion sequence element providing the promoter region for the expression of this gene immediately upstream of the gene.

\section{Genetic structure in relation to enterotoxin production}

Twenty-nine of the $93 \mathrm{~B}$. fragilis isolates of the collection were identified as ETBF by PCR experiments designed to detect the metalloprotease-enterotoxin-encoding gene. Excluding those isolates obtained from laboratories specifically working on ETBF (Sears et al., 1995; Pantosti et al., 1997b; Kato et al., 2000), this represents $18 \%$ of the population which was analysed. A similar proportion was found by Pantosti et al. (1994, 1997a) in Italy. Previous experiments showed complete agreement between in vitro cytotoxicity assays and the results of the PCR experiments amplifying $b f t-1, b f t-2$ and $b f t-3$ (the three alleles of the $b f t$ gene), suggesting that if the gene is present it is also expressed (Pantosti et al., 1997a; Chung et al., 1999). False negative results due to possible primer mutations or to the presence of a further $b f t$ allele are not likely since three different PCRs with different primers were performed.

The ETs marking the strains carrying $b f t$ were distributed in division I, but were not present in division II. Furthermore, they were not associated with particular clinical symptoms, nor clustered in a specific genetic group, which is not surprising in a nonclonal population like that of division I. Recent studies suggested a role for
ETBF in bacteraemia (Kato et al., 1996). However, out of 23 strains isolated from blood cultures only 4 carried the $b f t$ gene. This finding, together with the existence of a high number of healthy carriers (Pantosti et al., 1994, 1997b), does not support an association between ETBF and bacteraemia.

The data obtained using MLEE are in agreement with previous results based on antigen analysis (Myers \& Shoop, 1987), RFLP (Smith \& Callihan, 1992) and ribotyping (Leszkzynski et al., 1997), showing no particular feature that would place the ETBF strains within a distinct subgroup of $B$. fragilis. Recently, the $b f t$ gene has been localized on a pathogenicity islet (Moncrief et al., 1998; Franco et al., 1999). Pathogenicity islets, like the pathogenicity islands, are transmitted by horizontal gene transfer between bacterial populations. The mobility of these unstable DNA elements and the observation that the bft gene is found only in division I, which presents an apparently higher recombination rate, could explain the observed distribution of the enterotoxin gene in the $B$. fragilis population, independently from the presence of a particular cluster of genotypes.

The alignment of the $b f t$ gene DNA sequences of the 29 ETBF strains showed three distinct alleles in the population studied. By sequence alignment and PCR performed with primers obtained from N. Kato, the $B$. fragilis strains were shown to harbour only one of these three alleles, confirming that the different $b f t$ alleles do not coexist (Franco et al., 1997). The distribution of the sequences in the two clusters was independent of the host origin or clinical manifestation (Table 1). bft-3 may represent the only exception, since this allele was absent from European and American isolates, supporting the idea of Chung et al. (1999) that the third bft allele may have originated by a different molecular evolution specific to Asian B. fragilis. An interesting finding was the high degree of sequence conservation: the $294 \mathrm{bp}$ amplicon showed no mutations within each allele and 14 point mutations between $b f t-1$ and $b f t-2$ (except 1475, showing two point mutations with respect to the other $b f t-2$ sequences). This conservation should be further investigated, since the primers used have not been designed to amplify a highly conserved DNA region, such as the zinc-binding site. Also $b f t$-3 seems to be highly conserved and allows a similar observation as for $b f t-1$ and $b f t-2$ : an alignment of $b f t-3$ (N. Kato, GenBank accession number AB026624), bft-Korea (Chung et al., 1999) and the amplicon obtained from GAI20240 showed no mutation between the three sequences.

\section{Genetic structure in relation to clinical manifestation}

The number of ETs observed, the absence of ETs represented by a large number of isolates and the absence of particular genotypes associated with distinct clinical manifestations showed that in B. fragilis populations, pathogenicity (invasiveness) is not caused by a few specific genomic types or clones. No particular clusters of $B$. fragilis were implicated in bacteraemia, abscesses or other clinical manifestations. 


\section{Genetic structure of the $B$. fragilis population colonizing patients}

Invasive $B$. fragilis seem not to present a genomic group distinct from those of the intestinal flora and patients could be colonized by isolates of different genotypes, e.g. ET 21, 13 and 76 from patient 64.

\section{Genetic structure of $B$. fragilis in different hosts}

ETs representing $B$. fragilis isolated from animals did not form a separate cluster and were randomly distributed among the ETs representing the human strains. However, only four animal strains were included in the analysis of $B$. fragilis and they may not be representative.

\section{Conclusion}

The observations inferred from MLEE are based on a panel of genes representing the chromosome as a whole and not on a single gene or a unique region of the genome. The data obtained strongly correlated with those provided by other techniques (DNA-DNA hybridization, ribotyping, RFLP, AP-PCR and $16 \mathrm{~S}$ rRNA), allowing the differentiation of $B$. fragilis into two subgroups associated with different antibiotic resistance traits (cepA and $c f A$ ). Three alleles of an enterotoxin-encoding gene ( $b f t-1, b f t-2$ and $b f t-3)$ were identified in the population. The production of the enterotoxin does not, however, seem to be related to a particular genomic group and seems not to represent a distinctive feature for invasive strains. No definite clones of $B$. fragilis are associated with specific clinical manifestations or geographical origin. Patients are thus infected by $B$. fragilis belonging to a wide variety of genomic types, supporting the hypothesis that $B$. fragilis is largely opportunistic or that invasive bacteria acquire by horizontal gene transfer a gene encoding an as yet unidentified virulence factor.

\section{ACKNOWLEDGEMENTS}

We thank J. Bille, E. Collatz, T. Hofstad, N. Kato, J. Meyer, J. Nicolet, A. Pantosti, M. Sebald and R. Zbinden for supplying bacterial strains. We also thank $N$. Kato for supplying the primers for the detection of $b f t-3$ and for helpful discussions, and E. Collatz, A. Pantosti, I. Podglajen, J. Musser and P. Boerlin for revising the manuscript.

This research was supported by grant 31-45914.95 from the Swiss National Science Foundation and by the Helmut Horten Foundation.

\section{REFERENCES}

Aeschbacher, M. \& Piffaretti, J.-C. (1989). Population genetics of human and animal enteric Campylobacter strains. Infect Immun 57, 1432-1437.

Akimoto, S., Ono, T., Tsutsui, H., Kinouchi, T., Kataoka, K. \& Ohnishi, Y. (1994). Complete sequence of the Bacteroides fragilis YCH46 neuraminidase-encoding gene. Biochem Biophys Res Commun 203, 914-921.
Balmelli, T. \& Piffaretti, J.-C. (1996). Analysis of the genetic polymorphism of Borrelia burgdorferi sensu lato by multilocus enzyme electrophoresis. Int J Syst Bacteriol 46, 167-172.

Boerlin, P. \& Piffaretti, J.-C. (1995). Multilocus enzyme electrophoresis. Methods Mol Biol 46, 63-68.

Boerlin, P., Rocourt, J. \& Piffaretti, J.-C. (1991). Taxonomy of the genus Listeria by using multilocus enzyme electrophoresis. Int J Syst Bacteriol 41, 59-64.

Boerlin, P., Peter, O., Bretz, A.-G., Postic, D., Baranton, G. \& Pifaretti, J.-C. (1992). Population genetic analysis of Borrelia burgdorferi isolates by multilocus enzyme electrophoresis. Infect Immun 60, 1677-1683.

Brook, I. \& Mihal, M. L. (1991). Adherence of Bacteroides fragilis group species. Infect Immun 59, 742-744.

Brook, I., Myhal, L. A. \& Dorsey, C. H. (1992). Encapsulation and pilus formation of Bacteroides spp. in normal flora abscesses and blood. J Infect 25, 251-257.

Brown, A. H. D., Feldman, M. W. \& Neveo, E. (1980). Multilocus structure of natural populations of Hordeum spontaneum. Genetics 96, 523-536.

Chung, G. T., Franco, A. A., Wu, S., Rhie, G. E., Cheng, R., Oh, H. B. \& Sears, C. L. (1999). Identification of a third metalloprotease toxin gene in extraintestinal isolates of Bacteroides fragilis. Infect Immun 67, 4945-4949.

Duimstra, J. R., Myers, L. L., Collins, J. E., Benfield, D. A., Shoop, D. S. \& Bradbury, W. C. (1991). Enterovirulence of enterotoxigenic Bacteroides fragilis in gnotobiotic pigs. Vet Pathol 28, 514-518.

Franco, A. A., Mundy, L. M., Trucksis, M., Wu, S., Kaper, J. B. \& Sears, C. L. (1997). Cloning and characterization of the Bacteroides fragilis metalloprotease toxin gene. Infect Immun $\mathbf{6 5}$, 1007-1013.

Franco, A. A., Cheng, R. K., Chung, G. T., Wu, S., Oh, H. B. \& Sears, C. L. (1999). Molecular evolution of the pathogenicity island of enterotoxigenic Bacteroides fragilis strains. J Bacteriol 181, 6623-6633.

Go, M. F., Kapur, V., Graham, D. Y. \& Musser, J. (1996). Population genetic analysis of Helicobacter pylori by multilocus enzyme electrophoresis: extensive allelic diversity and recombinational population structure. J Bacteriol 178, 3934-3938.

Harris, H. \& Hopkinson, D. A. (1976). Handbook of Enzyme Electrophoresis in Human Genetics (and Supplement 1978). Amsterdam: North-Holland Publishing Co.

Johnson, J. L. (1978). Taxonomy of Bacteroides. I. Deoxyribonucleic acid homologies among Bacteroides fragilis and other saccharolytic Bacteroides species. Int J Syst Bacteriol 28, 245-256.

Kato, N., Kato, H., Watanabe, K. \& Ueno, K. (1996). Association of enterotoxigenic Bacteroides fragilis with bacteremia. Clin Infect Dis 23, Suppl. 1, S83-S86.

Kato, N., Liu, C., Kato, H., Watanabe, K., Tanaka, Y., Yamamoto, T., Suzuki, K. \& Ueno, K. (2000). A new subtype of the metalloprotease toxin gene and the incidence of the three $b f t$ subtypes among Bacteroides fragilis isolates in Japan. FEMS Microbiol Lett 182, 171-176.

Khushi, T., Payne, D. J., Fosberry, A. \& Reading, C. (1996). Production of metal dependent beta-lactamases by clinical strains of Bacteroides fragilis isolated before 1987. J Antimicrob Chemother 37, 345-350.

Kleivdal, H. \& Hofstad, T. (1995). Chromosomal restriction endonuclease analysis and ribotyping of Bacteroides fragilis. APMIS 103, 180-184.

Leszkzynski, P., Van Belkum, A., Pituch, H., Verbrugh, H. \& 
Meisel-Mikolajczyk, F. (1997). Vaginal carriage of enterotoxigenic Bacteroides fragilis in pregnant women. J Clin Microbiol 35, 2899-2903.

Loos, B. G., Dyer, D. W., Whittam, T. S. \& Selander, R. K. (1993). Genetic structure of populations of Porphyromonas gingivalis associated with periodontitis and other oral infections. Infect Immun 61, 204-212.

Moncrief, J. S., Obiso, R., Jr, Barroso, L. A., Kling, J. J., Wright, R. L., Van Tassell, R. L., Lyerly, D. M. \& Wilkins, T. D. (1995). The enterotoxin of Bacteroides fragilis is a metalloprotease. Infect Immun 63, 175-181.

Moncrief, J. S., Dunkan, A. J., Wright, R. L., Barroso, L. A. \& Wilkins, T. D. (1998). Molecular characterization of the fragilysin pathogenicity islet of enterotoxigenic Bacteroides fragilis. Infect Immun 66, 1735-1739.

Moraes, S. R., Goncalves, R. B., Mouton, C., Seldin, L., Ferreira, M. C. \& Domingues, R. M. (1999). Bacteroides fragilis isolates compared by AP-PCR. Res Microbiol 159, 257-263.

Myers, L. L. \& Shoop, D. S. (1987). Antigenic characteristics of enterotoxigenic and nonenterotoxigenic isolates of Bacteroides fragilis. Am J Vet Res 48, 643-645.

Myers, L. L., Shoop, D. S., Collins, J. E. \& Bradbury, W. C. (1989). Diarrheal disease caused by enterotoxigenic Bacteroides fragilis in infant rabbits. J Clin Microbiol 27, 2025-2030.

Nagy, E., Szoke, I., Gacs, M. \& Csiszar, K. (1995). Resistance to beta-lactam antibiotics and beta-lactamase production of Bacteroides, Porphyromonas and Prevotella strains. Acta Microbiol Immunol Hung 42, 287-299.

Pantosti, A., Piersimoni, C. \& Perissi, G. (1994). Detection of Bacteroides fragilis enterotoxin in the feces of a child with diarrhea. Clin Infect Dis 19, 809-810.

Pantosti, A., Colangeli, R., Tzianabos, A. O. \& Kasper, D. L. (1995). Monoclonal antibodies to detect capsular diversity among Bacteroides fragilis isolates. J Clin Microbiol 33, 2647-2652.

Pantosti, A., Malpeli, M., Wilks, M., Menozzi, M. G. \& D'Ambrosio, F. (1997a). Detection of enterotoxigenic Bacteroides fragilis by PCR. J Clin Microbiol 35, 2482-2486.

Pantosti, A., Menozzi, M. G., Frate, A., Sanfilippo, L., D'Ambrosio, F. \& Malpeli, M. (1997b). Detection of enterotoxigenic Bacteroides fragilis and its toxin in stool samples from adults and children in Italy. Clin Infect Dis 24, 12-16.

Piffaretti, J.-C., Kressebuch, H., Aeschbacher, M., Bille, J., Bannerman, E., Musser, J. M., Selander, R. K. \& Rocourt, J. (1989). Genetic characterization of the bacterium Listeria monocytogenes causing epidemic disease. Proc Natl Acad Sci USA 86, 3818-3822.

Podglajen, I., Breuil, J. \& Collatz, E. (1994). Insertion of a novel DNA sequence, IS1186, upstream of the silent carbapenemase gene $c f i A$, promotes expression of carbapenem resistance in clinical isolates of Bacteroides fragilis. Mol Microbiol 12, 105-114.

Podglajen, I., Breuil, J., Casin, I. \& Collatz, E. (1995). Genotypic identification of two groups within the species Bacteroides fragilis by ribotyping and by analysis of PCR-generated fragment patterns and insertion sequence content. J Bacteriol 177, 5270-5275.

Rasmussen, B. A., Gluzman, Y. \& Tally, F. P. (1990). Cloning and sequencing of the class $\mathrm{B}$ beta-lactamase gene $(\mathrm{ccr} A)$ from Bacteroides fragilis TAL3636. Antimicrob Agents Chemother 34, 1590-1592.

Ruimy, R., Podglajen, I., Breuil, J., Christen, R. \& Collatz, E. (1996). A recent fixation of $c f i A$ genes in a monophyletic cluster of
Bacteroides fragilis is correlated with the presence of multiple insertion elements. J Bacteriol 178, 1914-1918.

Russo, T. A., Thompson, J. S., Godoy, V. G. \& Malamy, M. H. (1990). Cloning and expression of the Bacteroides fragilis TAL2480 neuraminidase gene, nanH, in Escherichia coli. J Bacteriol 172, 2594-2600.

Sack, R. B., Myers, L. L., Almeido-Hill, J., Shoop, D. S., Bradbury, W. C., Reid, R. \& Santosham, M. (1992). Enterotoxigenic Bacteroides fragilis: epidemiologic studies of its role as a human diarrhoeal pathogen. J Diarrhoeal Dis Res 10, 4-9.

Sack, R. B., Albert, M. J., Alam, K., Neogi, P. K. \& Akbar, M. S. (1994). Isolation of enterotoxigenic Bacteroides fragilis from Bangladeshi children with diarrhea: a controlled study. J Clin Microbiol 32, 960-963.

San Joaquin, V. H., Griffis, J. C., Lee, C. \& Sears, C. L. (1995). Association of Bacteroides fragilis with childhood diarrhea. Scand J Infect Dis 27, 211-215.

Scotto D'Abusco, A., Del Grosso, M. \& Pantosti, A. (1998). Characterization of the enterotoxin gene of Bacteroides fragilis strains from different human sources. In Abstracts of the 2nd World Congress on Anaerobic Bacteria and Infections, Nizza, 1998, abstract 3.106, p. 56. International Society of Anaerobic Bacteria.

Sears, C. L., Myers, L. L., Lazenby, A. \& Van Tassell, R. L. (1995). Enterotoxigenic Bacteroides fragilis. Clin Infect Dis 20, Suppl 2, S142-S148.

Selander, R. K., Caugant, D. A., Ochman, H., Musser, J. M., Gilmour, M. N. \& Whittam, T. S. (1986). Methods of multilocus enzyme electrophoresis for bacterial population genetics and systematics. Appl Environ Microbiol 51, 873-884.

Smith, C. J. \& Callihan, D. R. (1992). Analysis of rRNA restriction length fragment polymorphisms from Bacteroides spp. and Bacteroides fragilis isolates associated with diarrhea in humans and animals. J Clin Microbiol 30, 806-812.

Tally, F. P. \& Jacobus, N. V. (1983). Susceptibility of anaerobic bacteria to imipenem. J Antimicrob Chemother 12, Suppl D, 47-51.

Thompson, J. S. \& Malamy, M. H. (1990). Sequencing the gene for an imipenem-cefoxitin-hydrolyzing enzyme (cfiA) from Bacteroides fragilis TAL2480 reveals strong similarity between cfiA and Bacillus cereus beta-lactamase II. J Bacteriol 172, 2584-2593.

Tzianabos, A. O., Onderdonk, A. B., Smith, R. S. \& Kasper, D. L. (1994). Structure-function relationships for polysaccharideinduced intra-abdominal abscess. Infect Immun 62, 3590-3593.

Wayne, L. G., Brenner, D. G., Colwell, R. R. \& 9 other authors (1987). Report of the Ad Hoc Committee on Reconciliation of Approaches to Bacterial Systematics. Int J Syst Bacteriol 37, 463-464.

Wayne, L. G., Good, R. C., Bottger, E. C. \& 19 other authors (1996). Semantide- and chemotaxonomy-based analyses of some problematic phenotypic clusters of slowly growing mycobacteria, a cooperative study of the International Working Group on Mycobacterial Taxonomy. Int J Syst Bacteriol 46, 280-297.

Whittam, T. S., Ochman, H. \& Selander, R. K. (1983). Multilocus genetic structure in natural populations of Escherichia coli. Proc Natl Acad Sci USA 80, 1751-1755.

Received 13 October 1999; revised 20 January 2000; accepted 7 February 2000. 